\title{
Almas santas e aflitas nas Minas setecentistas
}

Holy and afflicted souls in Minas in the 1700s.

Les âmes saintes et affligées dans le Minas Gerais du XVIII'me siècle

Almas santas y afligidas en el Minas Gerais del siglo XVIII

William de Souza Martins ${ }^{[1]}$

\section{CAMPOS, Adalgisa Arantes. As irmandades de São Miguel e Almas do Purgatório: culto e iconografia no setecentos mineiro. Belo Horizonte: C/Arte, 2013}

$\longrightarrow$ uando a primeira versão deste trabalho veio à luz em 1994, constituída pela Tese de Doutorado apresentada à Faculdade de Filosofia, Letras e Ciências Humanas da Universidade de São Paulo, sob a orientação de Laura de Mello e Souza, tornou-se fonte de consulta indispensável aos especialistas do catolicismo no período colonial, particularmente aos interessados nas manifestações litúrgicas ligadas ao momento da morte. Desde então, a autora, professora titular do Departamento de História da Universidade Federal de Minas Gerais, publicou uma grande variedade de trabalhos dedicados, entre outros temas, ao culto aos santos e aos rituais da Paixão de Cristo, passando pela análise das representações iconográficas realizadas nas capelas e matrizes mineiras. A publicação da principal obra de Adalgisa Arantes Campos vem preencher uma lacuna importante no campo de estudos em que se situa e, além disso, coloca ao alcance de um círculo maior de leitores reflexões acerca dos rituais católicos do século XVIII que continuam válidas.

A autora estabelece um diálogo importante com a historiografia francesa, a quem cabe o pioneirismo no desbravamento deste campo temático, particularmente Michel Vovelle (1978; 2010), Jacques Le Goff (1993), Philippe Ariès (2014) e Jacques Chiffoleau (2011). Os três primeiros autores são considerados bastante representativos da chamada "história das mentalidades", que priorizou o estudo das representações coletivas que adquiriam permanência na "longa duração", conforme definição clássica de Fernand Braudel. A historiografia portuguesa é também visitada, com destaque no capítulo que dedica à análise da iconografia e da devoção às Almas em Portugal. Trata-se de um diálogo crítico, 
que rejeita a aplicação mecânica ao território das Minas coloniais de modelos de interpretação elaborados para as realidades do Velho Mundo.

Conforme argumenta Adalgisa Arantes Campos, existiram diversas especificidades do culto às Almas e das manifestações litúrgicas associadas à morte nas Minas entre 1712 e 1810, o recorte escolhido pela autora. Para compreendê-las, é indispensável ter em mente certas características da ocupação daquele território, marcada no primeiro quartel do século XVIII pela grande opulência material propiciada pelo ouro, ao qual se seguiu um lento e, depois de 1750, vertiginoso declínio. A proibição de fixação de ordens regulares na capitania teve o efeito de diminuir a quantidade de sacerdotes disponíveis para a celebração de missas, ofícios e outros rituais fúnebres associados às Almas do Purgatório. Paralelamente, devido à inexistência de mosteiros e de conventos, o culto às Almas ocupou os altares de capelas e de matrizes paroquiais, sobressaindo estas últimas, onde foram instaladas quase todas as irmandades que veneravam o Arcanjo São Miguel e as Almas do Purgatório.

No que diz respeito à leitura dos aspectos sociais e culturais mais amplos que nortearam a colonização daquele território, a autora se valeu de uma rica tradição de estudos do "barroco mineiro", em que avultam as edições patrocinadas pelo Instituto do Patrimônio Histórico e Artístico Nacional. ${ }^{1}$ Ao lado desse conjunto de estudos, a autora dialogou também com as obras que analisaram a atuação das irmandades na capitania das Minas (Salles, 1963; Boschi, 1986; Aguiar, 1997, p.80-106). Talvez um dos maiores méritos da obra resida na combinação das abordagens próprias da história da arte, aplicadas à análise das manifestações e dos modelos iconográficos, e da história social do território e das associações que veneravam as Almas do Purgatório e o Arcanjo São Miguel.

Da perspectiva das fontes escolhidas para a análise, a autora realiza um verdadeiro tour de force: fontes escritas de natureza normativa e litúrgica; farta documentação iconográfica; documentação de diferentes irmandades sob a invocação de São Miguel e Almas do Purgatório; tratados de meditação e oração, sermões e literatura. A escolha de material tão diversificado poderia conduzir à dispersão ou à análise superficial do material empírico. Pelo contrário, procedendo a partir da comparação, a análise sistemática dos detalhes produz uma visão orgânica do culto às Almas do Purgatório e dos rituais funerários na região das Minas. Estruturando a obra em cinco capítulos, pareceu acertada a decisão de não incluir o capítulo inicial da tese, dedicado à análise dos "novíssimos do homem" (a morte, o juízo, o inferno e o paraíso). ${ }^{2}$ Diminuindo-se o material de apoio, o livro ficou mais leve e mais focado no recorte escolhido.

A autora abre o primeiro capítulo com a discussão acerca do sistema teológico do Purgatório, que remete à grande obra de Jacques Le Goff. Na Idade Média, a constituição de um espaço intermediário ocupado pelos que morriam com pecados veniais, que mantinha simultaneamente união com o mundo dos vivos e dos santos, sublinhava as solidariedades e as trocas espirituais nos três

'Com relação ao primeiro grupo, ver: Oliveira (2006), Del Negro (1978), Trindade (1951), Lopes (1942), Passos (1940).

${ }^{2}$ A autora justificou a exclusão devido à publicação prévia do capítulo em Rezende e Villalta (2007). 
níveis em que se dividia a Igreja de Cristo. Conforme a própria autora assinalou em outro trecho:

O Purgatório tornou-se um tempo e lugar intermediários, constituindo no centro, na esperança, de muitas devoções. Os mortais ocupavam boa parte da sua vida terrena auxiliando as almas a resgatarem os próprios pecados e ascenderem na rota espiritual, rumo à imortalidade (p.68).

O capítulo inicial também apresenta a relação entre o culto às Almas e as descrições do Purgatório contidas na obra que exerceu profunda influência sobre as representações do além na sociedade ocidental: A divina comédia, de Dante Aliguieri. Na obra do poeta italiano, a purificação dos pecados por meio do fogo constituiu uma importante atividade realizada no espaço do Purgatório. Após a purgação obtida nesse espaço intermediário, as almas estavam prontas para receber as glórias do Paraíso. Aos homens que faleciam em pecado mortal, estavam reservadas as penas infinitas do Inferno, sem possibilidade de remissão. A autora assinala a complexidade do papel assumido pelo fogo no Purgatório: "ao mesmo tempo pune, rejuvenesce e imortaliza" (p.47, grifos no original). Ao consultar as imagens contidas nos livros das irmandades de São Miguel e Almas e outros testemunhos iconográficos das Minas, a autora percebe a continuidade, na "longa duração", do sistema de representações expresso por Dante:

\section{A análise sistemática dos detalhes produz uma visão orgânica do culto às Almas do Purgatório e dos rituais funerários na região das Minas}

As imagens expressam claramente a leitura do fogo enquanto elemento de purificação e santificação. Não há contorções, feições desfiguradas ou qualquer indício da natureza unívoca do fogo. As [Almas] eleitas atingidas pelo fogo conservam a serenidade, em sinal de meditação sobre o pecado e a esperança em Deus. Podemos ler o Purgatório de Dante, contemplando o acervo artístico proveniente das Minas do Ouro, como se este constituísse as pranchas ilustrativas daquela obra, tal é a afinidade entre as duas produções artísticas (p.47).

O capítulo dois trata da "iconografia e devoção às Almas em Portugal”. Trata-se de um importante material de apoio necessário à discussão dos capítulos centrais do livro. A partir do exame da historiografia portuguesa e da análise de diversas representações iconográficas existentes em diferentes localidades de Portugal, a autora constatou a variedade formal do culto às Almas efetuado no 
Reino. Chama inicialmente a atenção para as "alminhas", isto é, pequenos oratórios que se edificavam ao ar livre e que continham painéis alusivos às Almas do Purgatório. Os cruzeiros, cuja localização apresentava muita diversidade, mantinham igualmente uma relação direta com o referido culto. No que tange às confrarias das Almas, é possível verificar a existência de patronos diversificados, como São Francisco, São Gregório, São José etc.

No século XVIII, momento da organização do culto às Almas no território das Minas, observou-se uma redução da variedade constatada no Reino de Portugal: inexistência das "alminhas", o número de intermediários celestes associados à devoção às Almas ficou praticamente limitado ao Arcanjo São Miguel etc. No capítulo em questão, a autora trata ainda de deslocamentos ocorridos nas representações das Almas em Portugal, entre fins da Idade Média e princípios da Moderna. Enquanto no primeiro período a Virgem figurava em lugar de destaque no papel de intercessora das Almas do Purgatório, após o Concílio de Trento (1545-1563), Maria foi em parte substituída por outros intermediários celestes. Como hipótese para explicar essa mudança, a autora comenta que, para as sensibilidades clericais da modernidade, constituía uma ousadia figurar Nossa Senhora apertando os seios para aliviar com o seu leite a secura das almas padecentes (p.62 e 72).

\section{Seguindo tendências prenunciadas já na Idade Média, após o Concílio de Trento, o sacramento da eucaristia se tornou o principal sufrágio aplicado à salvação das Almas}

O capítulo três constitui o eixo do livro e contém talvez as principais contribuições da autora para o estudo da "economia da salvação" subjacente às representações do Purgatório (Araújo, 1997, p.387-436). Seguindo tendências prenunciadas já na Idade Média, após o Concílio de Trento, o sacramento da eucaristia se tornou o principal sufrágio aplicado à salvação das Almas (Le Goff, 1993, p.362). Neste contexto, as autoridades eclesiásticas se preocuparam em garantir a solenidade do uso litúrgico do corpo de Cristo, fiscalizando o estado dos templos e altares e até a aparência dos sacerdotes que celebravam o santo sacrifício, como também combatendo a utilização de hóstias em sortilégios e práticas mágicas.

Nas irmandades de São Miguel, além dos sufrágios constituídos por missas celebrados pelos irmãos falecidos - o que constituía também uma prática realizada por outras irmandades —, havia a instituição de capelanias de missas dedicadas ao conjunto das Almas do Purgatório. Na Irmandade de São Miguel da Matriz do Pilar de Vila Rica, tal capelania foi extinta em 1810, fato que foi destacado pela autora no desenvolvimento de um dos principais argumentos do terceiro capítulo: o declínio do culto às Almas ao longo do século XVIII. 
Tal declínio foi impactado pelo agravamento da situação econômica da capitania. Nesse ponto, percebe-se o diálogo implícito com a tese de Laura de Mello e Souza (1990) a respeito da pobreza no território das Minas setecentistas. A opulência de que se revestia o culto às Almas no primeiro quartel do século XVIII, caracterizado pela celebração de ofícios cantados com a participação de numerosos sacerdotes, músicos e decoração dos templos, foi substituída pela celebração silenciosa de missas em sufrágio das Almas. $\mathrm{O}$ culto às Almas vai assim perdendo espaço para a preocupação obsessiva com a salvação individual dos membros das irmandades de São Miguel. Para tanto, mesmo com as dificuldades econômicas assinaladas, as referidas irmandades aumentaram ao longo do século XVIII o número de sufrágios constituídos por missas, celebradas após o falecimento dos respectivos membros. Tal escolha revela a força da "contabilização do além" associada ao imaginário do Purgatório (Chiffoleau, 2011, p.127; Le Goff, 1993, p.269-271): o maior número de sufrágios tinha o efeito de apressar a passagem da alma pelo lugar intermediário, conduzindo-a ao Paraíso. Pelo fato de que, com algumas poucas exceções, os sacerdotes podiam apenas celebrar uma missa diariamente, a demanda maciça por sufrágios somente podia ser atendida fazendo-se celebrar as missas fora da capitania, de preferência na cidade do Rio de Janeiro ou no Reino de Portugal. Além dos vínculos afetivos existentes nesses territórios, a esmola para a celebração da missa era mais reduzida nos mesmos, devido à existência de maior número de sacerdotes. Por fim, a autora analisa o importante lugar ocupado nas rendas sacerdotais pelas missas de sufrágio e por outros atos litúrgicos associados ao momento da morte, o que permite compreender melhor a concentração de sacerdotes nas áreas mais urbanizadas da América Portuguesa, já apontada em estudo clássico (Neves, 1997, p.213-218).

O quarto capítulo foi destinado à análise de outros rituais, além da celebração de missas, que tinham relação com o culto às Almas do Purgatório: os ofícios, as procissões e as práticas de sepultamento. No que tange aos ofícios, a autora desenvolve em detalhes a tese do declínio de manifestações mais solenes ligadas ao culto das Almas, em decorrência não somente de dificuldades de ordem material, como também do "processo de aclimatação do universo religioso português" ao território das Minas (p.157). As procissões seguiram, em linhas gerais, o mesmo caminho. $\mathrm{O}$ estudo das práticas de sepultamento foi realizado de maneira meticulosa, a partir da base de dados dos livros de óbito da matriz do Pilar de Vila Rica. Na análise dos referidos registros, a autora reconstrói as hierarquias tecidas pelos irmãos de São Miguel e Almas e pelos fiéis em geral por ocasião do sepultamento. Por parte da população livre, havia preferência clara pela inumação no interior do templo, enquanto no adro deste sepultavam-se basicamente os escravos. Mesmo no interior do espaço sagrado da matriz havia diferenças entre o sepultamento na capela-mor, reservada a confrades de diferentes irmandades que tinham exercido cargos de direção em suas respectivas associações, e o sepultamento nas campas localizadas na nave templo paroquial. 
No último capítulo, a autora se dedica à análise da iconografia do Arcanjo São Miguel. Apoiando-se em estudos dedicados à análise dos modelos iconográficos e da história da arte (Belting, 2010; Male, 1984, entre outras referências), a autora constata as mudanças das representações de São Miguel e das Almas ocorridas no território das Minas, ante os padrões europeus. A autora faz também um mapeamento de cerca de 60 irmandades e devoções dedicadas à veneração do Arcanjo e das Almas do Purgatório que, em sua quase totalidade, impediam o ingresso de descendentes de africanos em suas fileiras. Talvez constitua uma lacuna da obra a ausência de maiores informações referentes aos irmãos das Almas, o que permitiria reconstituir o perfil prosopográfico dos mesmos. Em que pese isto, a obra de Adalgisa Arantes Campos constitui uma contribuição basilar ao estudo das representações acerca da morte e das práticas mortuárias no período colonial, um campo de estudos em que foi pioneira, ao lado das contribuições de João José Reis (1991) e de Cláudia Rodrigues (2005).

\section{Referências bibliográficas}

AGUIAR, Marcos Magalhães de. Capelães e vida associativa na capitania das Minas. Varia Historia, Belo Horizonte, n. 17, p.80-106, 1997.

ARAÚJO, Ana Cristina. A morte em Lisboa: atitudes e representações (1700-1830). Lisboa: Editorial Notícias, 1997.

ARIĖS, Philippe. O homem diante da morte. São Paulo: Unesp, 2014.

BELTING, Hans. Semelhança e presença: a história da imagem antes da era da arte. Rio de Janeiro: Ars Urbe, 2010.

BOSCHI, Caio César. Os leigos e o poder: irmandades leigas e política colonizador a em Minas Gerais. São Paulo: Ática, 1986.

CHIFFOLEAU, Jacques. La religion flamboyante: France (1320-1520). Paris: Éditions du Seuil, 2011. DEL NEGRO, Carlos. Nova contribuição ao estudo da pintura mineira (norte de Minas). Rio de Janeiro: Iphan, 1978.

LE GOFF, Jacques. O nascimento do Purgatório. Lisboa, Estampa, 1993.

LOPES, Francisco. História da construção da igreja do Carmo de Ouro Preto. Rio de Janeiro: Publicações do Sphan, 1942.

MALE, Émile. L'art religieux du XVIIe siècle: Italie, France, Espagne, Flandres. Paris: Armand Colin, 1984.

NEVES, Guilherme Pereira das. E receberá mercê: a Mesa da Consciência e Ordens e o clero secular no Brasil, 1808-1828. Rio de Janeiro: Arquivo Nacional, 1997.

OLIVEIRA, Myriam A. Ribeiro. O Aleijadinho e o santuário de Congonhas. Brasília: Iphan; Monumenta, 2006.

PASSOS, Zoroastro Viana. Em torno da história do Sabará: a Ordem Terceira do Carmo e sua igreja. Rio de Janeiro: Publicações do Sphan, 1940.

REIS, João José. A morte é uma festa: ritos fúnebres e revolta popular no Brasil do século XIX. São Paulo: Companhia das Letras, 1991.

REZENDE, Maria Efigênia Lage de; VILLANTA, Luís Carlos (Org.). História das Minas Gerais: as Minas setecentistas. Belo Horizonte: Autêntica; Companhia do Tempo, 2007. 2v.

RODRIGUES, Cláudia. Nas fronteiras do além: a secularização da morte no Rio de Janeiro (séculos XVIII e XIX). Rio de Janeiro: Arquivo Nacional, 2005.

SALLES, Fritz Teixeira de. Associações religiosas no ciclo do ouro. Belo Horizonte: Centro de Estudos Mineiros, 1963.

SOUZA, Laura de Mello e. Desclassificados do ouro: a pobreza mineira no século XVIII. 3. ed. Rio de Janeiro: Graal, 1990.

TRINDADE, Raimundo. São Francisco de Assis de Ouro Preto. Rio de Janeiro: Publicações do Sphan, 1951.

VOVELLE, Michel. As Almas do Purgatório ou o trabalho de luto. São Paulo, Unesp, 2010.

VOVELLE, Michel. Pieté baroque et déchristianisation en Provence au XVIIIe siècle. Paris: Éditions du Seuil, 1978. 